\title{
Clinical and Radiographic Findings of a Sliding Inguinoscrotal Bladder Hernia
}

\author{
Basri Cakiroglu ${ }^{\mathrm{a}, \mathrm{d}}$, Ilker Abcib ${ }^{\mathrm{b}}$, Yilmaz Bilsel ${ }^{\mathrm{b}}$, Hilmi Aksoy
}

\begin{abstract}
Cases of patients with inguinoscrotal hernia containing the urinary bladder, which also termed as "scrotal cystocele", are very rare. These patients usually present with frequent episodes of urinary tract infection, difficulty in walking, pollakiuria and difficulty in initiating micturition because of incarceration of the urinary bladder into the scrotum. The condition is often diagnosed incidentally, or during the course of surgical repair of inguinal hernia. We present a case of a large scrotal cystocele with preoperative findings and imaging.
\end{abstract}

Keywords: Inguinal hernia; Bladder; Bladder diverticula; Scrotal cystocele; Bladder hernia

\section{Introduction}

Many organs can be associated with inguinal hernias, but bladder hernia is a very uncommon condition with a frequency between $1 \%$ and $4 \%$ of all inguinal hernias [1]. Patients typically present clinically with scrotal swelling, obstructive urinary tract symptoms and the classic complaint of inability to completely empty the bladder [2].

Patients usually present with scrotal and inguinal swelling, and occasionally with the classic complaint of double

Manuscript accepted for publication January 14, 2014

${ }^{\mathrm{a}}$ Hisar Intercontinental Hospital Department of Urology, Saray Mah. Siteyolu Cad. No. 7, 34768 Umraniye, Istanbul, Turkey

${ }^{b}$ Hisar Intercontinental Hospital Department of Surgery, Saray Mah. Siteyolu Cad. No. 7, 34768 Umraniye, Istanbul, Turkey

${ }^{\mathrm{c}}$ Hisar Intercontinental Hospital Department of Radiology, Saray Mah. Siteyolu Cad. No. 7, 34768 Umraniye, Istanbul,Turkey

${ }^{\mathrm{d}}$ Corresponding author: Basri Cakiroglu, Hisar Intercontinental Hospital Department of Urology, Saray Mah. Siteyolu Cad. No. 7 , 34768 Umraniye, Istanbul, Turkey. Email: drbasri@gmail.com

doi: http://dx.doi.org/10.14740/jmc1654w voiding. Most are small hernias that are not of major clinical significance. On the other hand, scrotal bladder hernias are exceptional diagnostic and therapeutic challenges for both the urologists and general surgeons $[2,3]$.

\section{Case Report}

A 51-year-old morbidly obese male patient presented with chronic urinary retention and scrotal swelling, and needed to compress his scrotum to urinate. He is admitted to urology clinic with the complaint of becoming suddenly unable to void within 3 days, and his previous history is not significant. He had been involved in a traffic accident 15 years ago, but claimed no history of previous surgery. Physical examination revealed an obese man (weight, $120 \mathrm{~kg}$; height, 174 $\mathrm{cm}$ ). A large left hemiscrotum was suggestive of an inguinal hernia, and the prostate gland was normal sized, benign and nontender. The left hemiscrotum was enlarged and compressible without a solid mass. The left testicle, cord structures and external inguinal ring were not palpable. Computed tomography imaging of the pelvis demonstrated a large

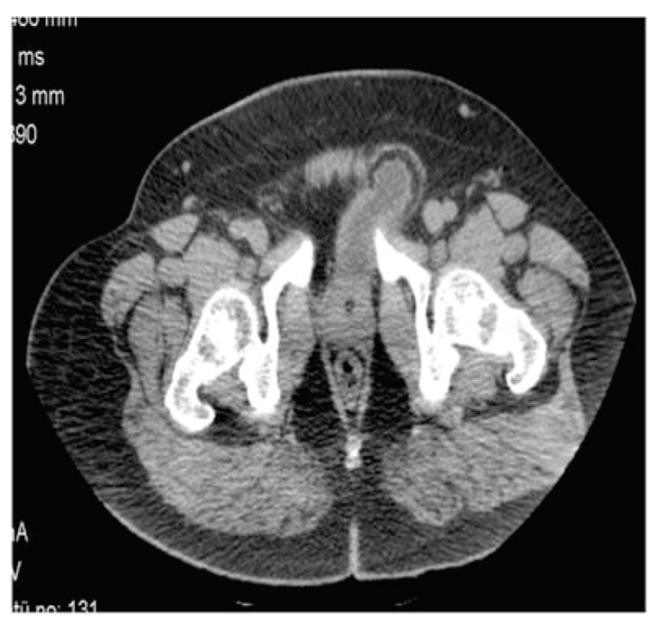

Figure 1. Coronal CT scan of left inguinal region, extending to the mesenteric adipose tissue reveals the bladder with left inguinal canal. Thickening of the bladder wall hernia was noticed at the level of the neck. 


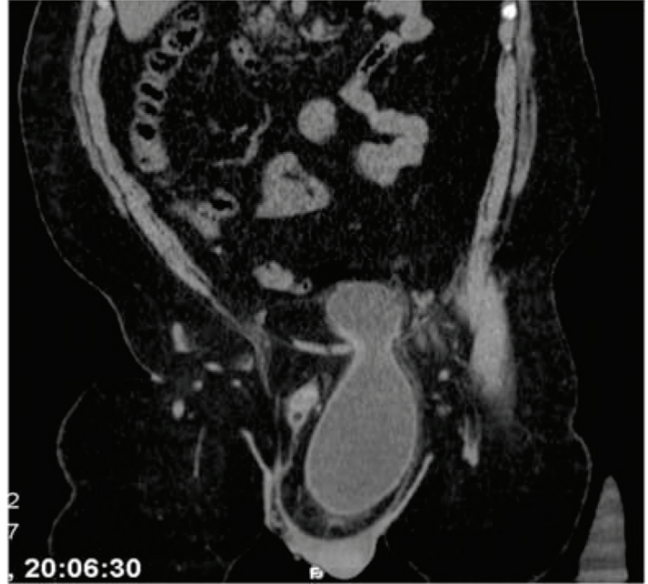

Figure 2. Axial CT scan shows that left inguinal hernia orifice area is quite narrow.

left inguinal sliding hernia of only the urinary bladder, and a cystogram confirmed the diagnosis of left scrotal cystocele, in addition to the bladder calculus (Fig. 1-3). Preceding herniorrhaphy, he underwent cystourethroscopy which did not reveal any urethral or bladder neck stricture, and showed that the ureteral orifices are within normal location. Additionally, no hydroureteronephrosis was seen on CT imaging, therefore no ureteral stent was inserted.

After preoperative left ureteral stent placement, the patient underwent a left groin exploration. It was found that there was a large sliding indirect inguinal hernia. When the hernia sac was opened, an incarcerated omentum together with entire left half of the bladder was found to be encompassed in the sac. Incarcerated omentum was excised, and the rest was reduced into the peritoneal cavity. After ligating and dividing attachments between the bladder and hernia sac, the bladder was reduced manually out of the scrotum, and a small insignificant bladder diverticulum was revealed. Bladder was replaced into the retroperitoneal space of Retzius, and a standard Lichtenstein herniorraphy was performed. Postoperative period was uneventful and the patient was discharged on postoperative second day.

\section{Discussion}

Herniation of urinary bladder is a relatively uncommon but not rare condition. However, isolated scrotal cystocele is very rare. It is important to recognize this condition in any men older than 50 years with inguinal hernia, as unknowingly, bladder injury during herniorrhaphy can lead to infection, sepsis or even death [2].

Bladder outlet obstruction, obesity and weakened pelvic musculature are predisposing factors [4]. Pathophysiological causes include decreasing bladder tonus or increasing laxity of the surrounding tissue in combination with bladder outlet

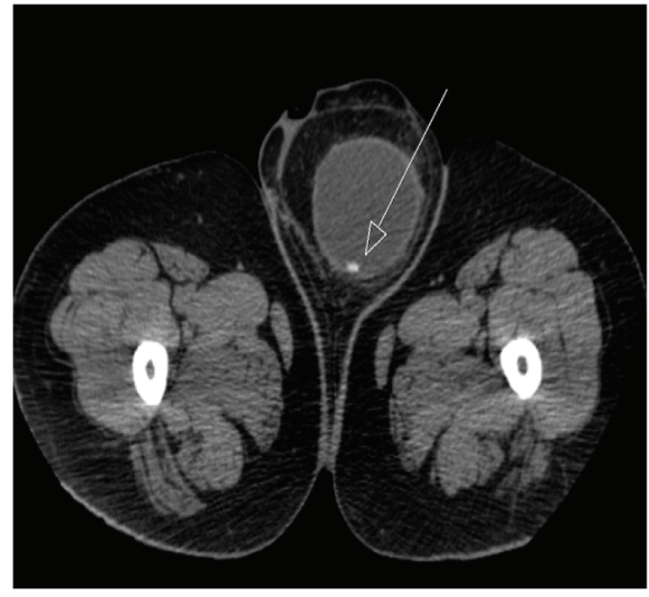

Figure 3. Axial CT scan shows that calculi in the urinary bladder is stretched hemiscrotum left inguinal canal.

obstruction. Increased abdominal pressure due to obesity is an important factor [5].

Majority of bladder hernias are extraperitoneal, more rarely paraperitoneal, and only exceptionally intraperitoneal. In view of the size of the hernia and distension of the bladder wall in the scrotum, the condition is described as a hernia of a bladder diverticulum or scrotal cystocele, although scrotal hernias of large vesical diverticuli have also been described $[6,7]$. Bladder hernias are usually asymptomatic, larger hernias that can cause voiding complaints related to bladder outlet obstruction and swelling of one side of the scrotum before micturation. Patients frequently describe the need to manually compress the scrotum to empty the bladder. Hematuria, pain, renal failure, incarceration and perforation can occur $[8,9]$.

Urinary bladder hernias are most commonly diagnosed intraoperatively during the hernia sac dissection or after inadvertent cystotomy. CT scan is also described as an important aid in diagnosing and outlining the anatomy of the affected area. MRI can also identify such lesions during studies of the abdomen and pelvis performed for unrelated purposes, or MRI can be used to clarify the findings seen on urography or sonography. The high resolution provided by MRI can allow analysis of the relationship of the hernia to the vascular landmarks and peritoneal structures, thus classifying the lesion as direct or indirect according to its position in relation $[7,10]$.

There are several treatment options, such as repositioning the protruded part of the bladder into the pelvis, or excising the affected part of the bladder. A surgical approach through an inguinal incision for bladder hernioraphy permits adequate access to the bladder and hernia sac. If a bladder hernia is incidentally found during hernioraphy, recommendations include either reduction of the bladder back to its anatomic location within Retzius' space or selective resection of the herniated bladder component, followed by standard inguinal hernia repair with or without mesh [1]. 
Our case is different from the literature simply as isolated bladder in the presence of the hernia sac.

\section{Conclusion}

Bladder herniation should be considered in the differential diagnosis of any inguinal, scrotal, or low abdominal wall hernia. Sliding inguinal hernias involving the urinary bladder often present with obstructive voiding symptoms and a scrotal mass. Large scrotal cystoceles are uncommon and warrant prompt surgical correction. Radiographic imaging aids the surgeon in fully defining the hernia contents and amount of bladder involvement prior to operative intervention. A tension-free herniorraphy should be performed for the correction of the underlying anatomical defect.

\section{Conflict of Interest}

All authors deny any meaningful affiliation or involvement, either direct or indirect, with any organization or entity with a direct financial interest in the subject matter or materials and any financial or material support for the work.

\section{References}

1. Oruc MT, Akbulut Z, Ozozan O, Coskun F. Urological findings in inguinal hernias: a case report and review of the literature. Hernia. 2004;8(1):76-79.

2. Bisharat M, O'Donnell ME, Thompson T, MacKenzie N, Kirkpatrick D, Spence RA, Lee J. Complications of inguinoscrotal bladder hernias: a case series. Hernia. 2009;13(1):81-84.

3. Zajaczkowski T. Scrotal bladder hernia: report of two cases. Int Urol Nephrol. 2007;39(2):479-484.

4. Casas JD, Mariscal A, Barluenga E. Scrotal cystocele: US and CT findings in two cases. Comput Med Imaging Graph. 1998;22(1):53-56.

5. Gomella LG, Spires SM, Burton JM, Ram MD, Flanigan RC. The surgical implications of herniation of the urinary bladder. Arch Surg. 1985;120(8):964-967.

6. Liebeskind AL, Elkin M, Goldman SH. Herniation of the bladder. Radiology. 1973;106(2):257-262.

7. Andac N, Baltacioglu F, Tuney D, Cimsit NC, Ekinci $\mathrm{G}$, Biren T. Inguinoscrotal bladder herniation: is $\mathrm{CT}$ a useful tool in diagnosis? Clin Imaging. 2002;26(5):347348.

8. Bjurlin MA, Delaurentis DA, Jordan MD, Richter HM 3rd. Clinical and radiographic findings of a sliding inguinoscrotal hernia containing the urinary bladder. Hernia. 2010;14(6):635-638.

9. Bell ED, Witherington R. Bladder hernias. Urology. 1980;15(2):127-130.

10. Catalano O. Computed tomography findings in scrotal cystocele. Eur J Radiol. 1995;21(2):126-127. 